\title{
Galantamine Activates Muscle-Type Nicotinic Acetylcholine Receptors without Binding to the Acetylcholine-Binding Site
}

\author{
Gustav Akk and Joe Henry Steinbach \\ Department of Anesthesiology, Washington University, St. Louis, Missouri 63110
}

Galantamine (Reminyl; Janssen Pharmaceutica, Titusville, NJ) belongs to a class of acetylcholinesterase inhibitors approved for symptomatic treatment of Alzheimer's disease. The drug presumably acts by raising and prolonging the profile of acetylcholine (ACh) via an inhibitory effect on the esterase. However, there is also evidence demonstrating that galantamine can activate the nicotinic ACh receptor or modulate its activation by ACh.

In this study, we have examined the ability of galantamine to directly activate the muscle-type nicotinic ACh receptor or to modulate receptor activation by selected nicotinic agonists.

Studies of direct activation by galantamine demonstrated that this ligand is a low-efficacy agonist of the muscle-type ACh receptor. Point mutations in the M2-M3 linker $(\alpha$ S269I) and the M2 transmembrane domain $(\epsilon \mathrm{T} 264 \mathrm{P})$ had similar effects on receptor activation by galantamine and nicotinic agonists, suggesting that the general features of receptor activation by galantamine are similar to that in the presence of ACh.

Experiments performed in the simultaneous presence of galantamine and various nicotinic ligands showed that channel activation by the nicotinic ligands studied (ACh, carbachol, and choline) was not affected by the presence of galantamine at concentrations up to 100 $\mu \mathrm{M}$. In addition, galantamine did not reduce the initial rate of binding for ${ }^{125} \mathrm{I}-\alpha$-bungarotoxin. These results demonstrate that galantamine does not interfere with the occupation of the nicotinic agonist binding site by ACh, carbachol, or choline. We conclude that galantamine activates the muscle-type ACh receptor by interacting with a binding site that is distinct from the site for nicotinic agonists.

Key words: acetylcholinesterase; channel; gating; binding; inhibition; block

\section{Introduction}

The muscle-type nicotinic acetylcholine $(\mathrm{ACh})$ receptor is normally activated after binding two ACh molecules. The interactions of ACh molecules with specialized binding pockets lead to generalized movement in the protein structure and opening of the channel gate. Although ACh serves as the major agonist in vivo, the receptor can be activated by a number of compounds, including tetramethylammonium, nicotine, and choline. All of these drugs act by binding to the ACh-binding site.

More recently, the activation of nicotinic receptors by a novel class of drugs, called allosterically potentiating ligands (APL), has been described (Pereira et al., 2002). The most commonly used APL-type ligands are galantamine and physostigmine, which are both plant-derived inhibitors of acetylcholinesterase (AChE). Both compounds had been used for symptomatic treatment of Alzheimer's disease and schizophrenic patients acting, presumably, through a mechanism of an increase and prolongation of the ACh concentration profile. There is, however, evidence demon-

\footnotetext{
Received Dec. 7, 2004; revised Jan. 12, 2005; accepted Jan. 13, 2005.

This work was supported by National Science Foundation Grant 0110282 (G.A.) and National Institutes of Health Grant NS-22356 (J.H.S.). J.H.S. is the Russell and Mary Shelden Professor of Anesthesiology. We thank Bei-Wen Ma for help with tissue culture.

Correspondence should be addressed to Gustav Akk, Department of Anesthesiology, Campus Box 8054, Washington University, 660 South Euclid Avenue, St. Louis, M0 63110. E-mail: akk@morpheus.wustl.edu. DOI:10.1523/JNEUROSCI.4985-04.2005

Copyright $\odot 2005$ Society for Neuroscience $\quad 0270-6474 / 05 / 251992-10 \$ 15.00 / 0$
}

strating that galantamine and physostigmine can directly activate or potentiate the nicotinic receptor function. In light of this, it has been proposed that a direct effect on the nicotinic receptor may contribute to the clinical actions of APLs (Maelicke and Albuquerque, 2000).

The interaction sites on the nicotinic receptor for APLs are not known. APL-elicited openings have been reported to be insensitive to the actions of the nicotinic competitive antagonists methyllycaconitine, $(+)$-tubocurarine, or $\alpha$-bungarotoxin $(\alpha \mathrm{BGT})$ (Okonjo et al., 1991; Pereira et al., 1993b; Storch et al., 1995), suggesting that APL-type ligands bind to a site not shared with nicotinic agonists. The existence of multiple classes of binding sites is well established for other ligand-gated ion channels. For example, the $\mathrm{GABA}_{\mathrm{A}}$ receptor can be activated by several classes of drugs that bind to nonoverlapping regions of the receptor: drugs such as GABA and muscimol interact with one site, barbiturates with another (Amin and Weiss, 1993), and steroids with yet another (Ueno et al., 1997).

In contrast, other studies have suggested that APLs interact with the ACh-binding site. For example, Zwart et al. (2000) found (2) that physostigmine potentiates the responses of $\alpha 4 \beta 4$ receptors to $\mathrm{ACh}$ at low concentrations but inhibits at higher concentrations and (2) that physostigmine displaces an AChbinding site ligand (epibatidine).

Most studies on nicotinic receptor activation by AChE inhibitors have been performed on the neuronal nicotinic receptor; 
relatively less is known about the effects of AChE inhibitors on the muscle-type receptor. The two types of receptors share a number of structural and functional properties. From the experimenter's point of view, however, the muscle-type receptor has several advantages. Most importantly, our understanding of the function of the muscle receptors is much more complete.

The present experiments were performed on adult and fetaltype muscle nicotinic receptors. The results demonstrate that galantamine is a low-efficacy agonist of the nicotinic receptor. The properties of channel activation produced by galantamine and nicotinic agonists are quite similar, indicating that the activated state is similar. However, both physiological and biochemical studies indicate that galantamine does not interact with the ACh-binding site. These observations suggest that activation of muscle-type nicotinic receptors can occur after ligand association with distinct sites on the receptor.

\section{Materials and Methods}

Mouse muscle nicotinic ACh receptor subunit $\operatorname{cDNAs}(\alpha, \beta, \gamma, \delta, \epsilon)$ were subcloned into a cytomegalovirus promoter-based expression vector (pcDNAIII; Invitrogen, San Diego, CA). The $\alpha$ S269I and $\epsilon$ T264P constructs were generously provided by Dr. A. Auerbach (State University of New York at Buffalo, Buffalo, NY). The receptors were transiently expressed in human embryonic kidney 293 (HEK 293) cells as described previously (Akk, 2002).

Chemicals were obtained from Sigma (St. Louis, MO). One sample of galantamine was a gift from Memory Pharmaceuticals (Montvale, NJ), and a second sample was purchased from Tocris Cookson (Ellisville, MO).

Electrophysiological experiments were performed using the singlechannel patch-clamp technique in the cell-attached configuration (Hamill et al., 1981; Akk, 2002). The bath solution contained (in mM): 140 $\mathrm{NaCl}, 5 \mathrm{KCl}, 1 \mathrm{MgCl}_{2}, 2 \mathrm{CaCl}_{2}, 10$ glucose, and 10 HEPES, pH 7.4. The pipette solution contained (in $\mathrm{mm}$ ): $142 \mathrm{KCl}, 1.8 \mathrm{CaCl}_{2}, 1.7 \mathrm{MgCl}_{2}, 5.4$ $\mathrm{NaCl}$, and 10 HEPES, pH 7.4. Agonists were added to the pipette solution. In most experiments, the patch potential was held at $-50 \mathrm{mV}$ using a combination of cell membrane potential and applied pipette potential. The cell membrane potential was determined (from the reversal potential of ionic currents) several times during the course of a recording from a patch. Most HEK 293 cells had a membrane potential of -50 to $-40 \mathrm{mV}$ in the bath solution used. All experiments were performed at room temperature.

Single-channel currents were amplified with an Axopatch 200B amplifier (Axon Instruments, Union City, CA), digitized at $500 \mathrm{kHz}$, and saved on a computer hard disk using a Digidata 1322 Series interface (Axon Instruments) for additional analysis. For long-term storage, the original data files were saved on DVD $+\mathrm{R}$ disks.

Channel event detection was performed using the segmental k-means algorithm (QuB suite; www.qub.buffalo.edu) (Qin et al., 1996, 1997). The currents were filtered at 3-6 kHz. Open and closed interval durations were estimated from the respective histogram using a maximum likelihood method ( $\mathrm{QuB}$ suite). For currents recorded in the presence of ACh or carbachol, analysis was restricted to clusters of single-channel currents that were isolated for additional analysis as described previously (Akk and Steinbach, 2003). In brief, series of relatively closely spaced openings, separated from other such groups by prolonged closed intervals, were defined as clusters. Clusters containing overlapping currents, which are an indication of more than two simultaneously active receptors, were discarded.

The channel effective opening rate is defined as an inverse of the duration of dwells in activatable (not desensitized or blocked) closed states of the receptor. In the presence of nicotinic ligands, the effective opening rate is determined as the inverse of the major component of intracluster closed-time histograms. The effective opening rate depends on receptor affinity to the agonist and channel gating properties and is used to describe the agonist concentration-response profile. When galantamine was coapplied with a nicotinic ligand, two major closed-time components were observed, one corresponding to the effective opening rate and the second arising from dwells in the blocked state. The effective opening rate was then determined by identifying the component for which duration was dependent on the concentration of the nicotinic ligand. For wild-type receptors exposed to galantamine only, the channel openings were not condensed into easily identifiable clusters; thus, the effective opening rate for such currents was not determined.

It was more complicated to determine the effective opening rate for the $\alpha$ S269I mutant receptor. Monoliganded openings (see Results) were prominent for $\alpha$ S269I receptors activated by low concentrations of galantamine. The presence of monoliganded open events leads to an artificial shortening of activation-related closed times, which result from dwells in the unliganded and monoliganded states. We addressed this issue by using a dead time of $1-1.5 \mathrm{~ms}$ when analyzing the closed-time histograms from these receptors activated by low concentrations $(<1$ $\mu \mathrm{M})$. By doing so, we eliminated all short (monoliganded) channel openings, concentrating instead on the longer-lived diliganded openings. The inverse durations between the diliganded (long-lasting) openings were defined as the effective opening rate.

Effective opening rate curves $\left(\beta^{\prime}\right)$ (see Figs. 2, 4, 5) were fit with the Hill equation:

$$
\beta^{\prime}=\beta /\left(1+\left(\mathrm{EC}_{50} /[\text { agonist }]\right)^{n}\right),
$$

where $\beta$ is the intrinsic channel opening rate constant, $\mathrm{EC}_{50}$ is the concentration of agonist producing a half-maximal effective opening rate, and $n$ is the Hill coefficient. Shifts in the estimates for $\beta$ or $\mathrm{EC}_{50}$ caused by a mutation or the presence of a modulator can be attributed to changes in receptor affinity to the agonist or the channel opening rate constant.

Voltage sensitivity was estimated from fitting the following equation:

$$
Z(V)=\left(Z_{0} \exp (V / H)\right),
$$

where $Z_{0}$ is the parameter value at $0 \mathrm{mV}$ membrane potential, $V$ is membrane potential, and $H$ is the change in membrane potential, which results in an e-fold change in duration. To convert $H$ into $f$ (the fraction of the electric field that would be traversed by a single positive charge), divide $25 \mathrm{mV}$ by $H$.

The results presented here are not confined to a particular activation scheme. Still, when presenting the data, we assumed the following activation scheme for the nicotinic receptor (Magleby and Stevens, 1972; Colquhoun and Hawkes, 1977):

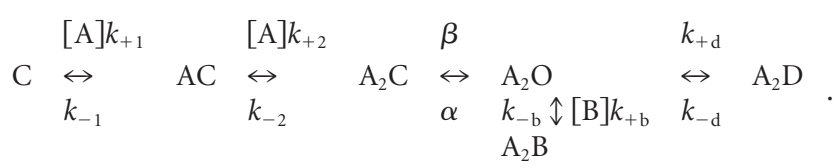

(Scheme 1)

According to Scheme 1, the closed, unliganded receptor (C) binds two agonist molecules, after which the channel opens $\left(\mathrm{A}_{2} \mathrm{O}\right)$. In Scheme 1, A is an agonist, $k_{+}$and $k_{-}$correspond to the agonist association and dissociation rate constants, $\beta$ is the channel opening rate constant, and $\alpha$ is the channel closing rate constant. The $\mathrm{A}_{2} \mathrm{D}$ state corresponds to a shortlived (1-5 ms) intracluster desensitized state (Colquhoun and Sakmann, 1985; Salamone et al., 1999) and should not be confused with the longlived desensitized state lasting seconds or minutes that terminates individual clusters (Auerbach and Akk, 1998). The $\mathrm{A}_{2} \mathrm{D}$ state is best observed for wild-type receptors activated by high concentrations of ACh or carbachol (see Fig. 4) or for the $\alpha$ S269I receptor activated by choline (see Fig. 5) when the effective opening rate is much faster than $k_{-\mathrm{d}}$. Rate constants $k_{+\mathrm{d}}$ and $k_{-\mathrm{d}}$ describe the transitions between the open and desensitized states. High concentrations $(\geq 10 \mu \mathrm{M})$ of galantamine resulted in the emergence of a new nonconducting state $\left(\mathrm{A}_{2} \mathrm{~B}\right)$; the prevalence of this state, but not the duration, depended on galantamine concentration. Rate constants $k_{+\mathrm{b}}$ and $k_{-\mathrm{b}}$ describe the transitions between the open state and the blocked state.

In the presence of micromolar concentrations of galantamine, the rate of entry into the short-lived desensitized state $\left(k_{+\mathrm{d}}\right)$ is usually much less than $k_{+\mathrm{b}}$ or $\alpha$. Therefore, a channel opening is predominantly terminated via two pathways, an entry into the blocked state $\left(k_{+\mathrm{b}}\right)$ and a true 
channel closing $(\alpha)$. The closed-time histograms were dominated by components arising from the blocked state (mean duration, $1 / k_{-\mathrm{b}}$ ) and from dwells in the activation pathway $\left(\mathrm{C}, \mathrm{AC}, \mathrm{A}_{2} \mathrm{C}\right.$; mean duration, $\left.1 / \beta^{\prime}\right)$. Under most conditions, the two closed states had widely differing durations and were easily distinguishable (see Results).

The initial rate of binding for ${ }^{125} \mathrm{I}-\alpha \mathrm{BGT}$ (I- $\alpha \mathrm{BGT}$ ) was estimated using standard methods (Sine and Taylor, 1979; Kopta and Steinbach, 1994). I- $\alpha$ BGT was purchased from PerkinElmer (Boston, MA) and was used at a concentration of $5 \mathrm{~nm}$. Wild-type adult receptors were stably expressed in QT6 cells (Kopta and Steinbach, 1994), whereas receptors containing the $\alpha$ S269I subunit were transiently expressed in HEK 293 cells, as described above. Cells were harvested using trypsin $(0.05 \% \mathrm{w} / \mathrm{v})-$ EDTA $(0.02 \% \mathrm{w} / \mathrm{v})$ solution and resuspended in binding buffer containing (in mM): $5.4 \mathrm{NaCl}, 140 \mathrm{KCl}, 1.7 \mathrm{MgCl}_{2}, 1.8 \mathrm{CaCl}_{2}$, and 25 HEPES, $\mathrm{pH}$ 7.4 (adjusted with $\mathrm{NaOH}$ ), with $0.4 \%(\mathrm{v} / \mathrm{v})$ fetal bovine serum. Cells were aliquoted and preincubated in the presence or absence of a drug alone for $10 \mathrm{~min}, \mathrm{I}-\alpha \mathrm{BGT}$ was added to a final concentration of $5 \mathrm{nM}$, and the incubation was continued for $20 \mathrm{~min}$. Binding was stopped by the addition of (+)-tubocurarine (final concentration, $200 \mu \mathrm{M}$ ). Cells were collected by filtration on Whatman (Florham Park, NJ) GF-B filters presoaked in $4 \%(\mathrm{w} / \mathrm{v})$ powdered milk. All assays were conducted in a high potassium salt solution for consistency with the physiological recordings. Nonspecific binding was determined in all experiments using $200 \mu \mathrm{M}$ $(+)$-tubocurarine. Each experiment was performed in duplicate, and results were computed by subtracting nonspecific binding and normalizing to the binding in the absence of any competing ligand.

\section{Results}

\section{Direct activation of muscle-type nicotinic receptors by galantamine}

The mouse adult wild-type nicotinic receptor is activated by galantamine (for structures of activators used, see Fig. 1). Sample currents elicited by 0.1 and $10 \mu \mathrm{M}$ galantamine are shown in Figure $2 \mathrm{~A}$. Single-channel clusters were not observed, suggesting that galantamine is a low-efficacy agonist, that the $K_{\mathrm{d}}$ of the receptor to galantamine is much higher than $10 \mu \mathrm{M}$, or both. It has been noted previously that the nicotinic channel closing rate constant is relatively insensitive to the structure of the ligand used to activate the receptor, with the rates for most ligands lying between 1000 and $2000 \mathrm{~s}^{-1}$ (Akk and Auerbach, 1999). The results of our experiments demonstrate that the apparent channel closing rate constant measured for galantamine also falls into this range. The wild-type channel closing rate constant measured in the presence of $0.1 \mu \mathrm{M}$ galantamine was $1142 \pm 20 \mathrm{~s}^{-1}$ (membrane potential, $-50 \mathrm{mV}$; simultaneous fitting of openings from three patches; 6570 events). The absence of single-channel clusters prevented additional studies on the activation of the wildtype receptor by galantamine. The single-channel conductance of channels activated by galantamine was indistinguishable from that for receptors activated by nicotinic ligands $(\sim 70 \mathrm{pS}$ in these ionic conditions; data not shown), as has been reported previously for APLs (Pereira et al., 1993a; Storch et al., 1995; Cooper et al., 1996).

A number of mutations in the muscle-type nicotinic receptor have been shown to alter channel gating by nicotinic agonists. We asked whether mutations have similar effects on activation by galantamine. First, we examined the activation of the $\alpha$ S269I mutant receptor by galantamine. This mutation is known to increase the channel gating efficacy for $\mathrm{ACh}$ and choline by increasing the channel opening rate constant $(\sim 30$-fold $)$ and decreasing the channel closing rate constant (approximately threefold) (Zhou et al., 1999; Grosman et al., 2000). The underlying mechanism is unknown, but it is believed that the $\alpha \mathrm{S} 269$ site and its neighboring residues in the M2-M3 linker form the link between the agonist binding site and channel gate.

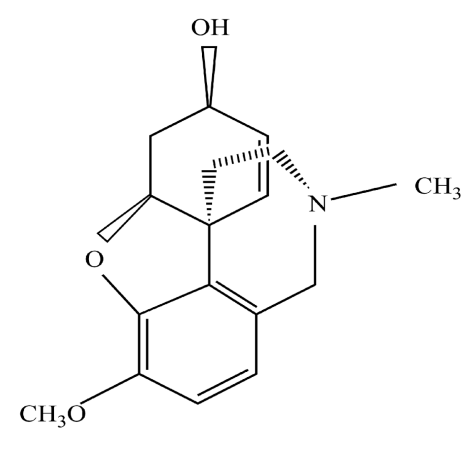

\section{Galantamine}<smiles></smiles>

Acetylcholine<smiles></smiles>

\section{Carbachol}

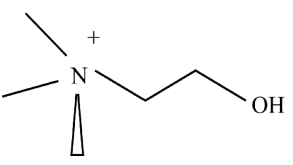

\section{Choline}

Figure 1. Structures of nicotinic receptor activators. The structures of the nicotinic receptor activators used (galantamine, $\mathrm{ACh}$, carbachol, and choline) are shown. The results show that galantamine activates the receptor without interacting with the traditional ACh-binding site, also shared by carbachol and choline.

Sample currents elicited by galantamine from receptors containing $\alpha$ S269I are shown in Figure 2B. Similarly to nicotinic ligands, galantamine-elicited channel openings are prolonged in the presence of the mutation. The mean open duration measured in the presence of $1 \mu \mathrm{M}$ galantamine was $5.9 \pm 0.1 \mathrm{~ms}$ (two patches;, 4965 events). At higher agonist concentrations, the open times are reduced. In the presence of $10 \mu \mathrm{M}$ galantamine, the mean open duration of the $\alpha$ S269I receptor is $2.6 \pm 0.03 \mathrm{~ms}$ (two patches; 14,764 events). The reduction in the apparent open duration is likely attributable to channel block (see below). At low galantamine concentrations, the open-time histograms contained two components with mean durations at $\sim 0.3 \mathrm{~ms}$ (brief) and $\sim 10 \mathrm{~ms}$ (long). The relative weights of the components were dependent on galantamine concentration. At a $0.1 \mu \mathrm{M}$ concentration of galantamine, $68 \%$ of openings (from two patches; 1971 events) belonged to the brief class, whereas at a $0.5 \mu \mathrm{M}$ concentration of galantamine, the brief and long openings were approximately equal in number (brief, 47\%; two patches; 1222 events). In the presence of $1 \mu \mathrm{M}$ galantamine, the brief component was relatively infrequent $(<20 \%)$. Based on the relative durations (for nicotinic ligands, monoliganded openings are shorter than diliganded openings) and the concentration sensitivity of the relative fractions, we believe that many of the brief openings arise from receptors that are not fully occupied by galantamine, whereas the longer-duration openings result from receptors with the maximum possible number of bound galantamine molecules.

The closed-time component for which duration depends on 
A

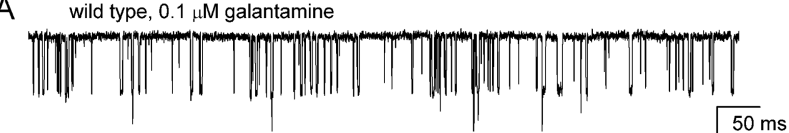

wild type, $10 \mu \mathrm{M}$ galantamine

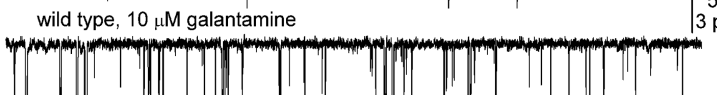

,

B
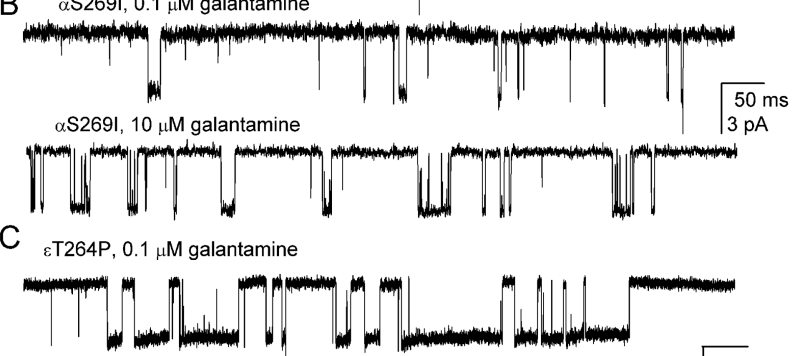

$\varepsilon \mathrm{T} 264 \mathrm{P}, 10 \mu \mathrm{M}$ galantamine

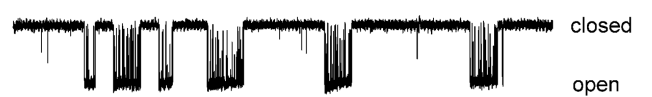

open
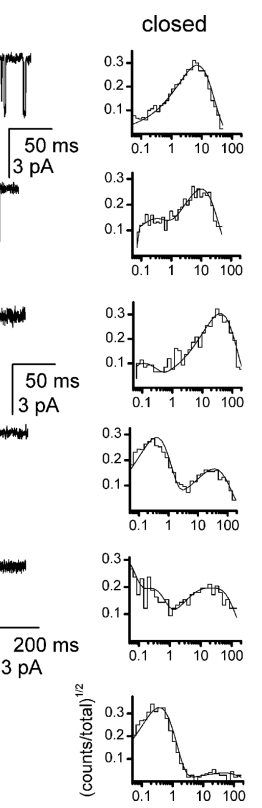

interval duration (ms)

Figure 2. Single-channel currents from wild-type and mutant receptors activated by galantamine. $\boldsymbol{A}$, Galantamine is a lowefficacy agonist of the wild-type receptor. Receptor activity takes place as isolated openings without any indication of singlechannel clusters. Occasional overlaps seen in the records indicate that at least two activatable channels were in the patch, suggesting that the true opening frequency of a single ion channel is less than what can be seen in the figure. For closed-time (CT) and open-time (OT) analysis, portions of the records without overlaps were used. The $\mathrm{CT}$ and $0 \mathrm{~T}$ histograms were fitted to a single exponential with $0.1 \mu \mathrm{m}$ galantamine (CT, $6.0 \pm 0.1 \mathrm{~ms} ; 0 \mathrm{~T}, 0.80 \pm 0.02 \mathrm{~ms})$. In the presence of $10 \mu \mathrm{m}$ galantamine, two components were seen in the CT histogram ( $0.21 \pm 0.04$ and $8.3 \pm 0.3 \mathrm{~ms})$ and one component in the 0 T histogram $(0.70 \pm 0.17$ $\mathrm{ms}$ ). The short-lived component in the (T histogram likely corresponds to dwells in the blocked state (see Results). Because of the uncertainty in the number of channels in the patch, the value of the longer-lived CT component cannot be interpreted. $\boldsymbol{B}$, The $\alpha S 269$ I mutation significantly enhanced $0 \mathrm{~T}$ durations and the opening frequency. In the presence of $0.1 \mu \mathrm{m}$ galantamine, the mean CTs were $0.09 \pm 0.03$ and $34.5 \pm 1.2 \mathrm{~ms}$. The mean 0Ts were $0.26 \pm 0.02$ and $12.7 \pm 0.8 \mathrm{~ms}$. We believe that the shorter-lived openings arise from a monoliganded open state. With $10 \mu \mathrm{m}$ galantamine, the mean $0 \mathrm{~T}$ duration was $2.6 \pm 0.05$ $\mathrm{ms}$. The CT histogram was fitted with the sum of two exponentials ( $0.34 \pm 0.01$ and $30.3 \pm 0.9 \mathrm{~ms})$. C, The $\epsilon$ T264P mutation greatly enhances gating efficacy. In the presence of $0.1 \mu \mathrm{m}$ galantamine, three components were observed in the $0 \mathrm{~T}$ histogram $(0.05 \pm 0.01,0.63 \pm 0.30$, and $41.7 \pm 2.8 \mathrm{~ms})$. We believe that the three components arise from unliganded, monoliganded, and diliganded receptors, respectively. The best fit of the CT histogram was achieved with four components $(0.02 \pm 0.01,0.21 \pm$ $0.04,5.8 \pm 3.3$, and $32.3 \pm 11.5 \mathrm{~ms}$ ). No attempt to assign the individual components to specific processes of receptor activation was made. With $10 \mu \mathrm{m}$ galantamine, the mean open duration was $3.6 \pm 0.02 \mathrm{~ms}$, likely reflecting openings from diliganded components. The disappearance of unliganded and monoliganded openings is a result of a higher agonist concentration. The relatively shorter duration of openings compared with the longest-lived component at a $0.1 \mu \mathrm{m}$ concentration of galantamine is probably a result of channel block. The CT histogram was fitted to the sum of two exponentials ( $0.32 \pm 0.01$ and $40 \pm 6.4 \mathrm{~ms})$. The shorter component likely reflects dwells in the blocked state.

agonist concentration was identified, and the inverse of the mean duration was defined as the effective opening rate $\left(\beta^{\prime}\right)$. The relationship between $\beta^{\prime}$ and galantamine concentration is given in Figure 3. Fitting Equation 1 to the data obtained from $\alpha$ S269I receptors gives a channel opening rate constant of $51 \mathrm{~s}^{-1}$, a Hill coefficient for activation of 1.6, and an $\mathrm{EC}_{50}$ of $700 \mathrm{nM}$. Assuming that the mutation affects the channel opening rate similarly for galantamine and choline, we estimate the opening rate constant of the wild-type receptor in the presence of galantamine is $\sim 2 \mathrm{~s}^{-1}$.

The nicotinic receptor gating properties are known to depend on membrane potential, and the channel closing rate constant is slowed e-fold by $\sim 80 \mathrm{mV}$ of hyperpolarization (Auerbach et al., 1996; Akk and Steinbach, 2000). The reason for this is unknown but has been attributed to movements of charged residues or dipoles in the protein structure (Magleby and Stevens, 1972; Auerbach et al., 1996). A difference in voltage sensitivity of gating would indicate a dissimilarity in protein dynamics during the gating reaction. We measured the voltage sensitivity of gating of $\alpha$ S269I receptors activated by $1 \mu \mathrm{M}$ galantamine. The mutant presence of ACh (Chen and Auerbach, 1998). At higher concentrations of galantamine, the open-time histograms contain a single component, likely reflecting the loss of spontaneous and monoliganded openings. With $10 \mu \mathrm{M}$ galantamine, the single remaining component has a mean duration of $3.6 \pm 0.02 \mathrm{~ms}$ (the reduced open duration reflects channel block; see below).

Finally, some cells were transfected with the $\alpha, \beta, \delta$, and $\gamma$ subunits, resulting in the fetal-type of muscle nicotinic receptor. The actions of galantamine on fetal-type receptors were similar to those seen on adult-type receptors. Isolated openings were seen in the presence of 0.1 or $1 \mu \mathrm{M}$ galantamine, which had a mean duration of $\sim 4 \mathrm{~ms}$ (at $-50 \mathrm{mV}$ ) and a mean single-channel conductance of $\sim 50 \mathrm{pS}$ (data not shown). The longer duration and lower conductance seen with the fetal-type receptors agree with a wealth of previous studies (Pereira et al., 1993; Storch et al., 1995; Cooper et al., 1996) demonstrating similar differences when receptors are activated by nicotinic ligands.

The results presented above demonstrate that galantamine is a low-efficacy agonist of the muscle-type nicotinic receptor. Channel 
gating in the presence of galantamine is not qualitatively different from that in the presence of nicotinic ligands. In particular, the open channel conductance and apparent closing rates are not greatly different, and the Hill coefficient for activation by galantamine is $>1$. Mutations known to affect gating by ACh have similar effects on gating elicited by galantamine, suggesting that the domains involved in gating by the two types of agonists are common.

Blocking actions of galantamine

At higher concentrations of galantamine, channel open durations were reduced, and a large number of brief dwells in a nonconducting state were seen (Fig. 4). These observations are consistent with an open channel block at higher concentrations of galantamine, as has been reported for a number of other positively charged nicotinic agonists (Adams, 1976; Ogden and Colquhoun, 1985). The observations were similar when channel openings were elicited by ACh $(5 \mu \mathrm{M})$ or carbachol $(100 \mu \mathrm{M})$ from wild-type receptors or elicited by galantamine $(100 \mu \mathrm{M})$ from receptors containing the $\alpha$ S269I subunit.

The rate of entry into the blocked state in the presence of $100 \mu \mathrm{M}$ galantamine $\left(V_{\mathrm{M}}-50 \mathrm{mV}\right)$ was 2035,2837 , or $2383 \mathrm{~s}^{-1}$ in the presence of $\mathrm{ACh}$, carbachol, and galantamine, respectively. In the presence of $10 \mu \mathrm{M}$ galantamine, the apparent blocking rate was $282 \mathrm{~s}^{-1}$ (ACh). Assuming a firstorder reaction, the association rates are $2.0-2.8 \times 10^{7} \mathrm{M}^{-1} \mathrm{~s}^{-1}$. The duration of the blocked state was also similar in the different conditions: $0.31,0.35$, and 0.39 $\mathrm{ms}$ in the presence of $100 \mu \mathrm{M}$ galantamine and $0.35 \mathrm{~ms}$ in the presence of $10 \mu \mathrm{M}$ galantamine. Galantamine did not affect the estimated apparent channel closing rates for activity elicited by ACh or carbachol (100 $\mu \mathrm{M}$ galantamine: $\alpha^{\prime}$ for ACh, 1009 $\mathrm{s}^{-1}$ vs $1093 \mathrm{~s}^{-1}$ control; carbachol, 1389 $s^{-1}$ vs $1536 s^{-1}$ control). The observation that the duration of the blocked state did not increase when the galantamine concentration was increased suggests that a single galantamine molecule is involved in block, in contrast to observations made for tacrine block of muscle-type nicotinic receptors (Prince et al., 2002).

Channel block by ions often shows voltage sensitivity; in the case of block by cationic drugs, the block is enhanced at more negative membrane potentials (Woodhull, 1973). Block by galantamine is increased at more negative membrane potentials. The dissociation constant (calculated from association and dissociation rates estimated over the potential range from -25 to $-100 \mathrm{mV}$ ) is reduced e-fold per $30-40 \mathrm{mV}$ (data not shown), which corresponds to a single positive charge sensing $\sim 74 \%$ of the membrane field in moving from the extracellular medium to the binding site.

A

B

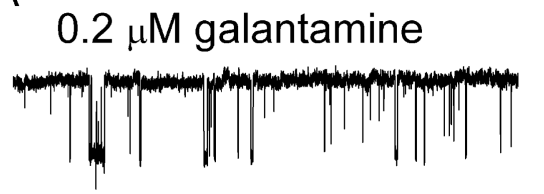

$0.5 \mu \mathrm{M}$ galantamine

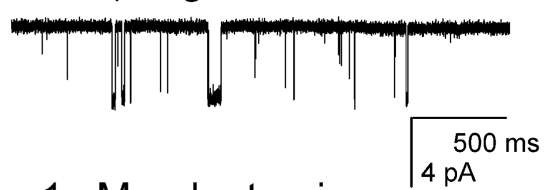

$1 \mu \mathrm{M}$ galantamine
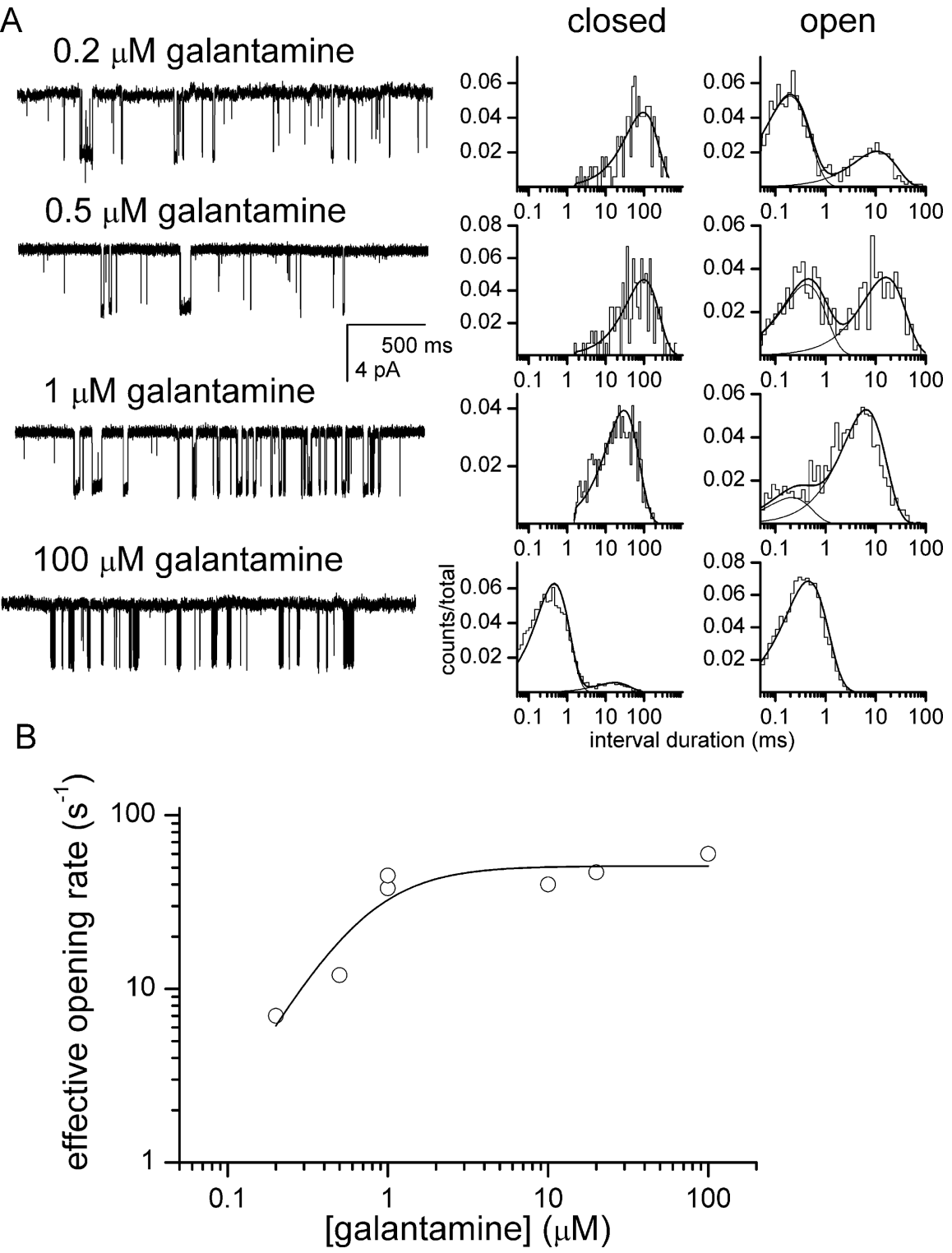

Figure 3. Activation of the $\alpha S 269$ I receptor by galantamine. $\boldsymbol{A}$, Sample currents elicited by $0.2,0.5$, or $1 \mu \mathrm{m}$ galantamine. Open-time (OT) and closed-time (CT) histograms. The dead time used in fitting the CT histograms at a $0.2-1 \mu \mathrm{m}$ concentration of galantamine was $1.5 \mathrm{~ms}$ to eliminate the reduction in duration of activation-related channel closures by monoliganded openings (see Materials and Methods). The mean (Ts were $135 \pm 16 \mathrm{~ms}(0.2 \mu \mathrm{m}), 83 \pm 7 \mathrm{~ms}(0.5 \mu \mathrm{M})$, and $24.4 \pm 1.2 \mathrm{~ms}(1 \mu \mathrm{M})$. The dead time used in fitting the $0 \mathrm{~T}$ histograms was $36-45 \mu \mathrm{s}$. The mean 0 Ts were $0.18 \pm 0.01$ and $9.8 \pm 0.7 \mathrm{~ms}(0.2 \mu \mathrm{m}), 0.38 \pm 0.04$ and $14.7 \pm 1.1 \mathrm{~ms}(0.5 \mu \mathrm{M})$, and $0.20 \pm 0.03$ and $6.0 \pm 0.2 \mathrm{~ms}(1 \mu \mathrm{M})$. $\boldsymbol{B}$, The channel effective opening rate is plotted as a function of galantamine concentration. Each symbol corresponds to data from one patch. At a $0.2-1 \mu \mathrm{m}$ concentration of galantamine, openings of $<1-1.5 \mathrm{~ms}$ were omitted from the calculation of the effective opening rate to avoid contamination by monoliganded openings (see Materials and Methods). The line was fitted using Equation 1. The best-fit parameters are as follows: $\beta, 51 \pm 10 \mathrm{~s}^{-} ; \mathrm{EC}_{50}, 0.7 \pm 0.3 \mu \mathrm{m}$ and $1.6 \pm 0.5$.

Galantamine-mediated modulation of nicotinic receptor activation

In the next set of experiments, we examined the modulating effect of galantamine on nicotinic receptor activation by three nicotinic agonists: ACh, carbachol, and choline. The approach relies on rapid competitive binding of two ligands at the same site, with one ligand having a much lower channel opening rate than the other. In this situation, the channel opening frequency is reduced below the value observed for the more efficacious agonist in the absence of the competing ligand, because the receptor spends a fraction of time liganded with one or two molecules of the poor agonist. For example, in studies of the weak traditional agonist 


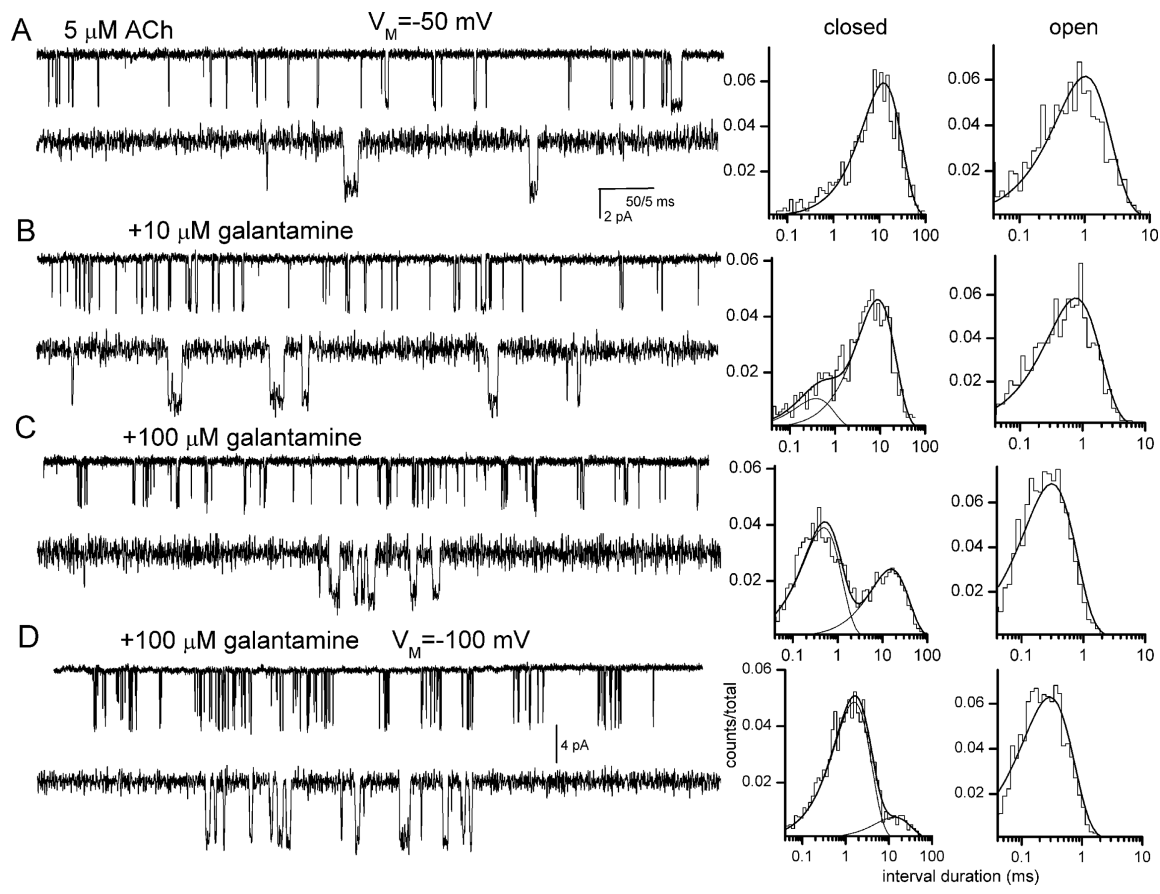

Figure 4. Galantamine blocks single-channel currents from the wild-type receptor activated by ACh. For each condition single-channel currents under two time resolutions as well as closed-time (CT) and open-time (OT) histograms are shown. An increase in galantamine concentration and/or hyperpolarization results in an increase in the relative number of blocked-related channel closures. $\boldsymbol{A}$, Single-channel currents elicited by $5 \mu \mathrm{m} \mathrm{ACh}$ at $-50 \mathrm{mV}$. The mean CT was $11.0 \pm 0.4 \mathrm{~ms}$, and the mean 0T was $0.94 \pm 0.03 \mathrm{~ms}$. $\boldsymbol{B}$, At a $10 \mu \mathrm{m}$ concentration of galantamine, the CT histograms were fitted by the sum of two exponentials The mean CTs were $0.35 \pm 0.06 \mathrm{~ms}(20 \%)$ and $7.9 \pm 0.3 \mathrm{~ms}(80 \%)$. The shorter-lived closed dwells arise from the blocked state. The mean $0 \mathrm{~T}$ was $0.72 \pm 0.02 \mathrm{~ms}$. C, The relative number of block-related channel closures is greater at $100 \mu \mathrm{m}$ galantamine, but the duration is unaffected. The mean CTs were $0.42 \pm 0.02 \mathrm{~ms}(65 \%)$ and $13.7 \pm 0.6 \mathrm{~ms}$ (35\%). The mean 0T was $0.28 \pm$ $0.01 \mathrm{~ms}$. $\boldsymbol{D}$, Hyperpolarization $(-100 \mathrm{mV}$ ) resulted in an increase in the relative number of block-related dwells and the prolongation of the lifetime of the blocked state. The mean CTs were $1.3 \pm 0.04 \mathrm{~ms}(78 \%)$ and $12.2 \pm 1.0 \mathrm{~ms}(22 \%)$. The mean 0 T was $0.27 \pm 0.01 \mathrm{~ms}$

TEA, the effective opening rate for activation by ACh or carbachol is reduced in the presence of TEA (Akk and Steinbach, 2003).

The first step was to study the effect of galantamine on singlechannel clusters elicited by carbachol from wild-type receptors. As a measure of receptor affinity and channel opening, we examined the modulation of the channel effective opening rate with 1 $\mathrm{mM}$ carbachol by increasing concentrations of galantamine. We estimated the effective channel opening rate to determine whether galantamine produced changes in the apparent affinity for carbachol or the channel opening rate. Figure 5 shows the effective opening rate with $1 \mathrm{~mm}$ carbachol in the presence of 0.2-100 $\mu \mathrm{M}$ galantamine. This concentration of carbachol results in a half-maximal value for $\beta^{\prime}$, so that a change in either the $\mathrm{EC}_{50}$ or maximal value would produce a shift. No major effect on the $\beta^{\prime}$ value was observed, suggesting that galantamine does not affect muscle-type nicotinic receptor affinity to carbachol or the channel opening rate constant. Potentiation of neuronal nicotinic receptor activation is maximal at $\sim 1 \mu \mathrm{M}$ galantamine (Samochocki et al., 2003), so we also examined the effect of $1 \mu \mathrm{M}$ galantamine on the effective opening rate in the presence of 500 $\mu \mathrm{M}$ carbachol. The data demonstrated no modulating effect of galantamine on receptor activation by a nicotinic ligand. The effective opening rate was $1309 \pm 17 \mathrm{~s}^{-1}$ (simultaneous fitting of pooled data from five patches; 85,283 events) for $500 \mu \mathrm{M}$ carbachol and $1493 \pm 14 \mathrm{~s}^{-1}$ (four patches; 78,837 events) for $500 \mu \mathrm{M}$ carbachol plus $1 \mu \mathrm{M}$ galantamine.

We then determined the dependence of $\beta^{\prime}$ on the concentra- tion of carbachol in the absence of galantamine or the presence of $100 \mu \mathrm{M}$ galantamine. As shown in Figure $5 C$, neither the $\mathrm{EC}_{50}$ nor the maximal value was affected.

We confirmed these results obtained with carbachol by examining the effects of galantamine on the effective opening rate produced by a low concentration of ACh. The channel opening rate for $\mathrm{ACh}$ is so large that the maximal value cannot be reliably estimated using our methods, while any potentiation might be most apparent at a low concentration of agonist. Receptor activation by a low concentration of ACh $(5 \mu \mathrm{M})$ was studied in the absence and presence of $100 \mu \mathrm{M}$ galantamine. The effective opening rate was $82 \pm 35 \mathrm{~s}^{-1}$ (three patches; 4028 events) and $92 \pm 18 \mathrm{~s}^{-1}$ (three patches; 18,422 events) for $5 \mu \mathrm{M}$ ACh and $5 \mu \mathrm{M}$ ACh plus $100 \mu \mathrm{M}$ galantamine, respectively. Hence, there was no indication that galantamine affected receptor affinity to ACh.

Finally, we examined the effect of galantamine on receptor activation by choline. These experiments were performed on the $\alpha$ S269I mutant receptor. The mutation enhances channel gating efficacy, turning the weak agonist choline into one that produces high open probability clusters. Sample clusters elicited by $500 \mu \mathrm{M}$ and $5 \mathrm{~mm}$ choline are shown in Figure $6 \mathrm{~A}$. From previous studies (see above), it has been determined that $1 \mu \mathrm{M}$ galantamine saturates the binding sites involved in activation by galantamine, whereas $1 \mu \mathrm{M}$ galantamine produces little channel block. Therefore, we examined how $1 \mu \mathrm{M}$ galantamine affects receptor activation by choline. The channel effective opening rates in the absence and presence of galantamine are shown in Figure $6 \mathrm{~B}$. The data indicate that the presence of galantamine has little effect on channel activation by choline.

It should be pointed out that there are some limitations to this approach. The approach requires that the ligands compete on a time scale appropriate to the duration of the relevant component of the closed-time distribution. Therefore, an inhibitor with a long dwell time, such as $(+)$-tubocurarine, would not show such interaction. However, this approach allows us to examine interactions between ligands with relatively low affinities.

In sum, these experiments demonstrate that the presence of galantamine does not affect receptor activation by the nicotinic ligands ACh, carbachol, or choline. Exposure to galantamine did not result in receptor potentiation, as had been observed previously for neuronal-type nicotinic receptors. Furthermore, to our surprise, there was no indication of galantamine-induced competitive inhibition of activation by a nicotinic ligand. These findings suggest that the interaction sites for galantamine and nicotinic ligands do not overlap.

\section{Galantamine effects on the binding of ${ }^{125} \mathrm{I}-\alpha \mathrm{BGT}$}

A second approach to determine whether a drug binds to the ACh-binding site is to determine whether it reduces the initial rate of I- $\alpha$ BGT binding (Sine and Taylor, 1979). For comparison 
A
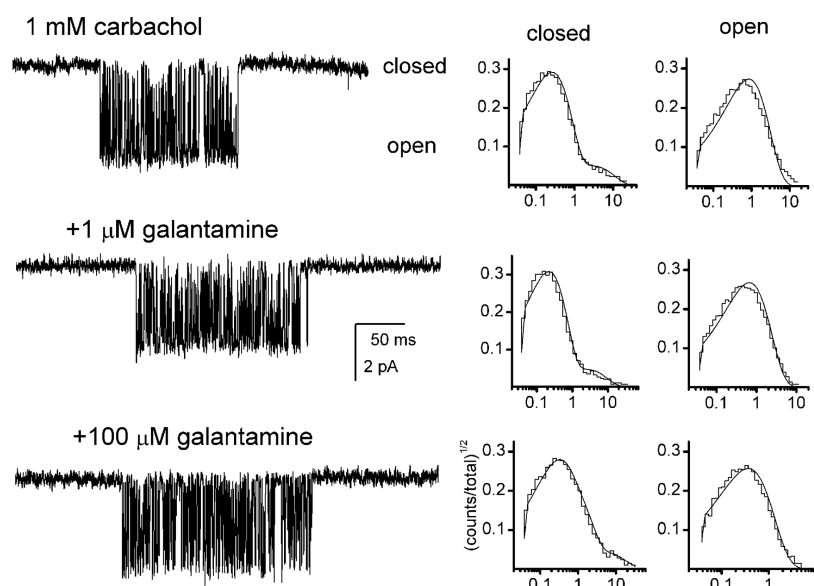

B
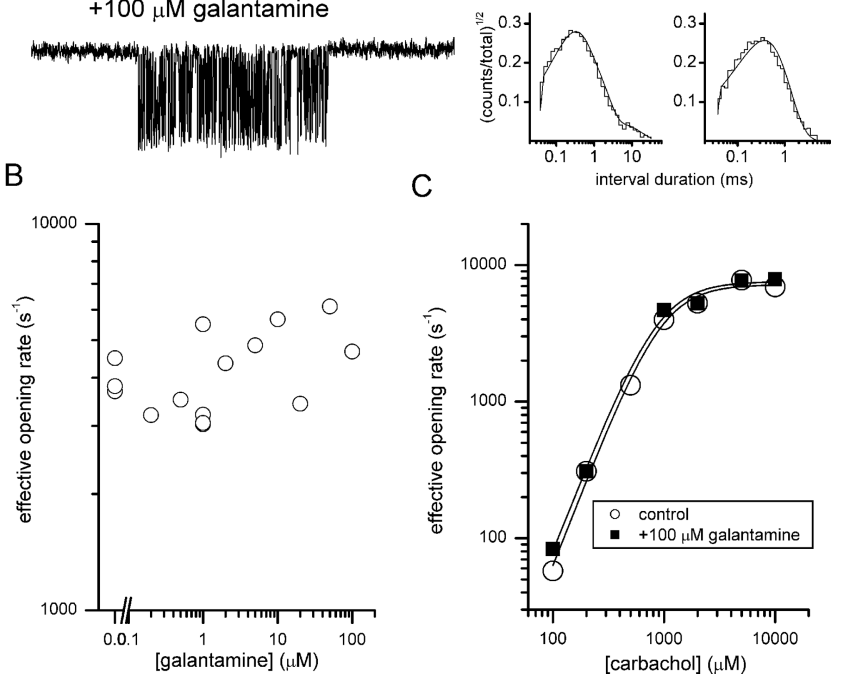

C

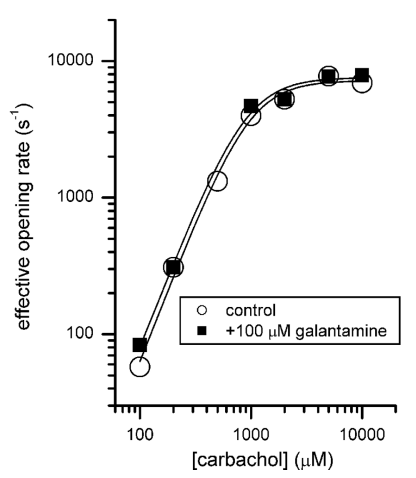

Figure 5. Effect of galantamine on wild-type receptors activated by carbachol. A, Singlechannel clusters recorded in the presence of $1 \mathrm{~mm}$ carbachol, carbachol plus $1 \mu \mathrm{m}$ galantamine, or carbachol plus $100 \mu \mathrm{m}$ galantamine. The presence of $100 \mu \mathrm{m}$ galantamine leads to a slight reduction in the open probability, because of channel block. The closed-time (CT) and opentime (OT) histograms from the respective patches are shown to the right. The $\mathrm{CT}$ histograms were fitted with two components for carbachol and carbachol plus $1 \mu \mathrm{m}$ galantamine and with three components for carbachol plus $100 \mu \mathrm{m}$ galantamine. The $0 \mathrm{~T}$ histograms were fitted to a single exponential. The results of the fit are as follows: At a $1 \mathrm{~mm}$ concentration of carbachol, the CTs were $0.22 \pm 0.003$ and $2.6 \pm 0.2 \mathrm{~ms}$, and the mean open duration was $0.68 \pm 0.01 \mathrm{~ms}$. The shorter-lived component in the $\mathrm{CT}$ distribution results from activation-related channel closures, and the longer-lived component corresponds to dwells in the $A_{2} D$ state (see Scheme 1). With carbachol plus $1 \mu \mathrm{m}$ galantamine, the CTs were $0.18 \pm 0.002$ and $2.3 \pm 0.2 \mathrm{~ms}$, and the $0 \mathrm{~T}$ was $0.52 \pm 0.004 \mathrm{~ms}$. With carbachol plus $100 \mu \mathrm{m}$ galantamine, the CTs were $0.21 \pm$ $0.01,0.65 \pm 0.06$, and $4.5 \pm 0.6 \mathrm{~ms}$, and the mean open duration was $0.31 \pm 0.003 \mathrm{~ms}$. The additional $(0.65 \mathrm{~ms})$ component in the CT histogram is attributable to dwells in the blocked state, and the reduction in the mean open time reflects the block process. $\boldsymbol{B}$, The effective opening rate at $1 \mathrm{~mm}$ carbachol in the absence and presence of 0.2-100 $\mu \mathrm{m}$ galantamine. Each data point corresponds to one patch. Overall, the data indicate that galantamine does not affect the effective opening rate. $\boldsymbol{C}$, The effective opening rate curves for carbachol in the absence and presence of $100 \mu \mathrm{m}$ galantamine. Each point corresponds to data from one patch. No data are shown for $500 \mu \mathrm{m}$ carbachol plus $100 \mu \mathrm{m}$ galantamine because of the similarities in the lifetimes for closed states arising from channel activation and block by galantamine. The curves were fitted with Equation 1. The results of the fit are as follows: $\beta, 7176 \pm 664 \mathrm{~s}^{-} ; \mathrm{EC}_{50}, 960 \pm$ $117 \mu \mathrm{m}, 2.1 \pm 0.1$ (control); $\beta, 7553 \pm 708 \mathrm{~s}^{-} ; \mathrm{EC}_{50,}, 903 \pm 147 \mu \mathrm{m} ; 2.1 \pm 0.2$ (plus $100 \mu \mathrm{m}$ galantamine). The results demonstrate that galantamine does not affect the binding or opening properties of the receptor, because neither the $\mathrm{EC}_{50}$ nor $\beta$ estimates are affected.

with results obtained with galantamine, the inhibition produced by carbachol was also determined. Galantamine at concentrations up to $100 \mu \mathrm{M}$ had no effect on I- $\alpha$ BGT binding to wild-type receptors, whereas carbachol inhibited with an $\mathrm{IC}_{50}$ of $40 \mu \mathrm{M}$ (Fig. 7A). The data for carbachol are similar to data obtained previously for wild-type adult receptors $(20-40 \mu \mathrm{M}$ ) (Sine and Taylor, 1979; Kopta and Steinbach, 1994). When receptors contained the $\alpha$ S269I subunit, the inhibition curve was shifted to the
A $500 \mu \mathrm{M}$ choline

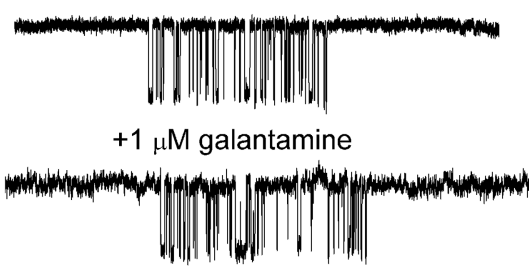

$5 \mathrm{mM}$ choline
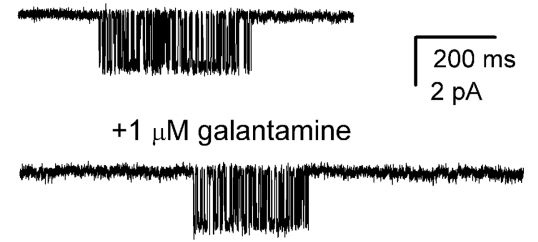

$B$

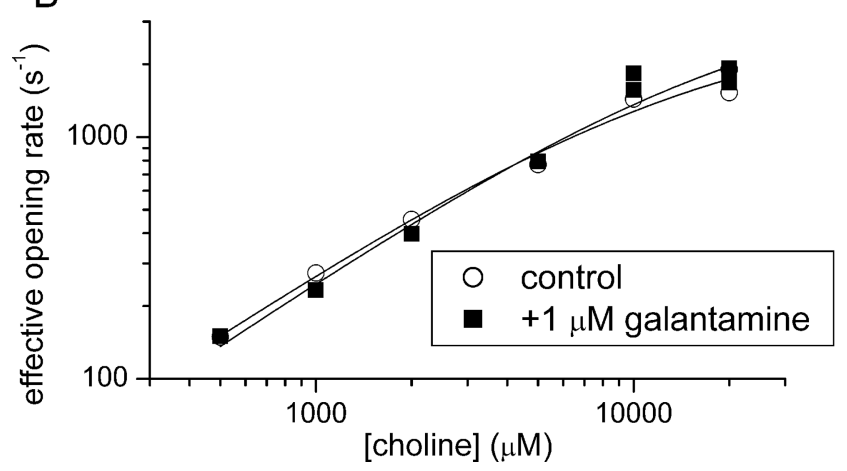

Figure 6. Effect of galantamine on $\alpha S 2691$ receptors activated by choline. $A$, Single-channel clusters recorded in the presence of $500 \mu \mathrm{m}$ or $5 \mathrm{~mm}$ choline or in the absence and presence of 1 $\mu \mathrm{m}$ galantamine, as well as corresponding intracluster closed-time (CT) histograms. With 500 $\mu \mathrm{m}$ choline, the mean CTs were $0.08 \pm 0.01$ and $7.2 \pm 0.2 \mathrm{~ms}$. With $500 \mu \mathrm{m}$ choline plus $1 \mu \mathrm{m}$ galantamine, the mean CTs were $0.11 \pm 0.01$ and $6.7 \pm 0.1 \mathrm{~ms}$. With $5 \mathrm{~mm}$ choline, the mean CTs were $1.3 \pm 0.03$ and $9.4 \pm 2.0 \mathrm{~ms}$. With $5 \mathrm{~mm}$ choline plus $1 \mu \mathrm{m}$ galantamine, the mean CTs were $1.3 \pm 0.02$ and $8.2 \pm 1.0 \mathrm{~ms}$. The closed-time histogram with $500 \mu \mathrm{m}$ choline alone shows two components. The longer-duration component includes both activation-related closures and dwells in the short-lived desensitized state. It is likely that the brief closed state primarily reflects immediate reopenings from the doubly liganded closed state. The longerduration component was interpreted as the effective opening rate. With $5 \mathrm{~mm}$ choline alone, the small contribution of the short-lived desensitized state can be resolved (mean duration, $9 \mathrm{~ms}$ ), while the component reflecting activation-related closures has shifted to briefer durations (1.3 $\mathrm{ms})$. Note that the presence of galantamine does not produce any change in the CT distributions. $\boldsymbol{B}$, The mutant channel effective opening rate is plotted as a function of choline concentration. The presence of $1 \mu \mathrm{m}$ galantamine has little effect on the effective opening rate value. For choline, the best-fit parameters are as follows: $\beta, 3062 \pm 1196 \mathrm{~s}^{-} ; \mathrm{EC}_{50}, 14.7 \pm 12.6 \mathrm{~mm}$ and $0.9 \pm 0.1$. For choline plus $1 \mu \mathrm{m}$ galantamine, the best-fit parameters are as follows: $\beta$, $4017 \pm 3034 \mathrm{~s}^{-} ; \mathrm{EC}_{50}, 21.2 \pm 31.1 \mathrm{~mm}$ and $0.9 \pm 0.2$.

left for carbachol ( $\mathrm{IC}_{50}, \sim 0.4 \mu \mathrm{M}$ ) (Fig. $7 B$ ), as would be expected from the shift in the concentration dependence of the probability of being open. However, galantamine still produced no inhibition, even at $100 \mu \mathrm{M}$. Galantamine is a larger molecule than carbachol, so the lack of inhibition by galantamine suggests that it does not occupy the ACh-binding site.

\section{Discussion}

The goal of the experiments described in this paper was to characterize the actions of galantamine on the muscle-type nicotinic receptor. Previous studies had indicated three possible effects: galantamine might directly activate the receptor, it might potentiate the ability of nicotinic agonists to activate the receptor, and 
A

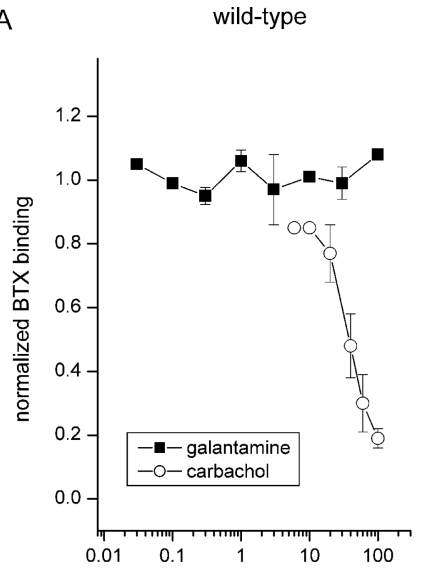

B

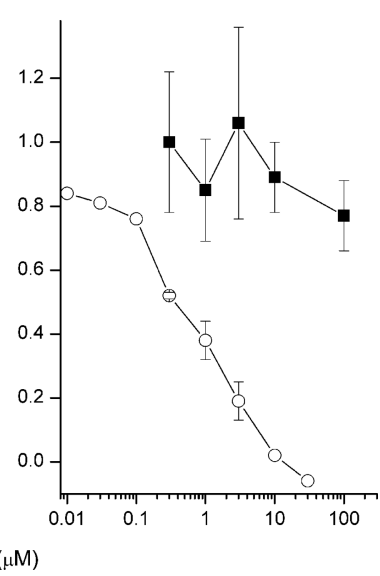

Figure 7. Galantamine does not reduce the initial rate of binding for $1-\alpha B G T$. $A$, The reduction in the initial rate of $\mathrm{I}-\alpha \mathrm{BGT}$ binding for wild-type adult receptors (expressed in QA-33 cells) by carbachol (open circles) and galantamine (filled squares). The $\mathrm{IC}_{50}$ for inhibition by carbachol is $\sim 38 \mu \mathrm{M}$, whereas that for galantamine is not defined in these data. $\boldsymbol{B}$, Similar data for adult receptors containing the $\alpha \mathrm{S} 269 \mathrm{l}$ subunit. The $\mathrm{IC}_{50}$ for inhibition by carbachol is shifted to $\sim 0.4$ $\mu \mathrm{M}$, but the $\mathrm{IC}_{50}$ for inhibition by galantamine is not defined (>1000 $\left.\mu \mathrm{M}\right)$. BTX, ${ }^{125} \mid-\alpha$-bungarotoxin.

it might inhibit receptor activation. Our results demonstrate that galantamine activates and inhibits the muscle-type nicotinic receptor yet has no potentiating effect on currents elicited by nicotinic agonists. More surprisingly, the data indicate that galantamine does not interact with the ACh-binding site on this receptor.

\section{Receptor activation by galantamine}

There are several similarities between the receptor activation produced by galantamine and traditional nicotinic agonists. This study and previous ones (Pereira et al., 1993a; Storch et al., 1995; Cooper et al., 1996) have found that the single-channel conductance of nicotinic receptors activated by APLs is similar to that of receptors exposed to ACh. Similarly, the voltage dependence of the channel closing rate is similar between nicotinic agonists and APLs. The relationship between the effective opening rate and the agonist concentration shows a Hill coefficient of $>1$, indicating that most receptors with open channels have more than one agonist molecule bound. However, galantamine is a nonefficacious agonist with a very low channel opening rate.

The effects of mutations on activation by galantamine were strikingly similar to the effects observed for receptors activated by nicotinic ligands. The $\alpha$ S269I and $\epsilon$ T264P mutations are known to enhance the channel gating efficacy for nicotinic ligands by increasing the channel opening rate and decreasing the channel closing rate. Our data show similar effects of the mutations on channel activation by galantamine.

Overall, these observations indicate strong similarities between receptor activation by nicotinic ligands and galantamine. The conductance and the channel closing rate (and its voltage dependence) are similar. Channels open more readily when two agonist molecules are bound. Finally, mutations in the transmembrane domains that affect channel opening and closing rates have similar effects on activity elicited by nicotinic agonists and by galantamine.

\section{Receptor inhibition by galantamine}

Galantamine produces a brief, voltage-dependent channel block. Block of single-channel currents by AChE inhibitors has been

observed previously (Shaw et al., 1985; Pereira et al., 1993a; Wachtel, 1993; Cooper et al., 1996; Prince et al., 2002). Block by galantamine is consistent with a simple, linear open channel blocking mechanism, as reported in some studies of cholinesterase inhibitors (Shaw et al., 1985; Pereira et al., 1993a; Wachtel, 1993; Cooper et al., 1996).

We did not see any evidence for inhibition mediated by competition for binding to the ACh-binding site or for allosteric effects on agonist affinity or channel opening rate.

\section{Interaction between galantamine and the traditional nicotinic agonist binding site}

We sought evidence for an interaction between galantamine and the nicotinic agonist binding site by examining the channel effective opening rate for the nicotinic agonist at various galantamine concentrations. In the present studies, we used three traditional nicotinic agonists. For two of them, we were able to obtain data for the full effective opening rate curve as a function of traditional agonist concentration, to show that there was no shift in the $\mathrm{EC}_{50}$ or $\beta$ estimates in the presence of galantamine. In the case of the receptor containing the $\alpha$ S269I subunit, we also were able to determine the relationship between the effective opening rate for activity elicited by galantamine and the galantamine concentration. In this case, a concentration of galantamine that produced a maximal effective opening rate had no effect on the effective opening rate for activation by choline.

Overall, these data demonstrate that galantamine has no interaction with receptor activation by classical nicotinic agonists, at least at concentrations up to $100 \mu \mathrm{M}$. Two interpretations follow from this observation. First, there is no indication that galantamine potentiates (or inhibits) the actions of nicotinic ligands by effects on affinity or opening rate. Second, there is no indication that galantamine binds to the ACh-binding site, at least in any manner that interferes with the binding of ACh, carbachol, or choline.

Because of the novelty of the second interpretation (that an activator of the muscle nicotinic receptor might act by binding to a site distinct from the ACh-binding site), we then examined the ability of galantamine to inhibit the initial rate of I- $\alpha$ BGT binding. Galantamine did not inhibit I- $\alpha$ BGT binding even at concentrations of $100 \mu \mathrm{M}$. The interpretation is most clear cut for the receptors containing the $\alpha$ S269I subunit, for which the physiological data indicated an $\mathrm{EC}_{50}$ for channel activation of $<1 \mu \mathrm{M}$ galantamine. The potency of agonists to inhibit I- $\alpha$ BGT binding is a consequence of the affinity of the agonist for the desensitized receptor. For example, the $\mathrm{EC}_{50}$ for activation by carbachol is $\sim 1$ $\mathrm{mm}$ (Akk and Auerbach, 1999), whereas the $\mathrm{IC}_{50}$ for inhibition of I- $\alpha$ BGT binding is $\sim 30 \mu \mathrm{M}$. For less-efficacious agonists, the values for the $\mathrm{EC}_{50}$ and $\mathrm{IC}_{50}$ are closer, but the $\mathrm{IC}_{50}$ is not larger than the $\mathrm{EC}_{50}$. Thus, the lack of inhibition by galantamine supports the idea that galantamine binding occurs to a region outside of the ACh-binding site, and sufficiently distant enough that galantamine does not protrude into the I- $\alpha \mathrm{BGT}$ region.

Previous studies of muscle receptors have provided conflicting observations. The activation of fetal-type muscle nicotinic receptors by galantamine or physostigmine could be blocked by $\alpha$ BGT or methyllycaconitine (Cooper et al., 1996), although a previous study of frog neuromuscular receptors found that $\alpha$ BGT could not block activation by physostigmine (but see Shaw et al., 1985; Pereira et al., 1993b). Okonjo et al. (1991) reported that the activation of Torpedo nicotinic receptors by physostigmine is not blocked by $(+)$-tubocurarine or $\alpha \mathrm{BGT}$ (but see Kawai et al., 1999). 
Studies of neuronal nicotinic receptors have generally been interpreted to indicate that APLs do not bind to the ACh-binding site on those receptors. Activation of single-channel currents from several types of neuronal nicotinic receptors by a number of APLs has been reported to be insensitive to inhibition by several drugs that block the ACh-binding site (Pereira et al., 1993a). In contrast, the monoclonal antibody FK1 does not block activation by drugs binding to the ACh-binding site (Pereira et al., 1993a) but does block both activation and potentiation by APLs (Pereira et al., 1993a; Samochocki et al., 2003). It has also been shown that galantamine (Dajas-Bailador et al., 2003) and physostigmine (Pabreza et al., 1991) do not inhibit binding of tritiated nicotinic ligands to $\alpha 4 \beta 2$-like receptors at concentrations up to $100 \mu \mathrm{M}$.

The most complete study (Zwart et al., 2000), however, has reported evidence that tacrine and physostigmine bind to the nicotinic binding site and that potentiation is mediated by the activation of heteroliganded receptors (e.g., receptors with one bound ACh molecule and one bound APL). The conclusion is based on the finding that the ability of tacrine and physostigmine to potentiate responses can be satisfactorily described by the predictions of the scheme, and in the case of physostigmine acting on $\alpha 4 \beta 4$ receptors, by the independently measured ability of physostigmine to inhibit epibatidine binding. There were several caveats to the study, however, such as the strong truncation of potentiation curves attributable to channel block and the fact that the prediction of a reduced slope at low ACh concentrations (because only one ACh molecule needs to bind to produce a heteroliganded receptor) is not seen (Samochocki et al., 2003); finally, there is some question about the ability of tacrine to act as an APL on neuronal nicotinic receptors (Samochocki et al., 2003).

Our results indicate that there are two (or more) classes of binding sites on each receptor, one for nicotinic agonists and another for galantamine. The occupation of either set of binding sites can lead to the opening of the channel gate. However, the data also show that channel activity elicited by even relatively low concentrations of a nicotinic agonist is not affected by the presence of a saturating concentration of galantamine (Fig. 6). This finding is rather surprising, because it might be expected, in the case of independent binding sites, that the presence of $1 \mu \mathrm{M}$ galantamine (with an effective opening rate of $50 \mathrm{~s}^{-1}$ ) would have affected the overall effective channel opening rate elicited in the presence of $500 \mu \mathrm{M}$ choline (with an effective opening rate of 140 $\left.\mathrm{s}^{-1}\right)$. Two possible explanations for the lack of apparent effect immediately come to mind. First, choline binding to the nicotinic binding site may prevent channel activation by galantamine. Such a mechanism would require the postulation of negative allosterism between an ACh binding site and a galantamine site. Alternatively, choline may competitively inhibit the binding of galantamine to the receptor yet be unable to elicit channel opening through the occupation of the galantamine site. Full resolution of the interactions between galantamine and nicotinic agonists will require more experiments.

\section{Galantamine binding site(s)}

Photoaffinity labeling with another AChE inhibitor, phenyl- ${ }^{3} \mathrm{H}$ physostigmine, labels Lys125 in the Torpedo nicotinic receptor $\alpha$ subunit (Schrattenholz et al., 1993). This residue forms part of the epitope for monoclonal antibody FK1 (Schroder et al., 1994) but is not part of the nicotinic agonist binding site (Brejc et al., 2001). It remains to be determined in future studies (1) whether galantamine and physostigmine interact with the receptor via the same binding sites and (2) what other residues contribute to receptor interaction with $\mathrm{AChE}$ inhibitors.

\section{References}

Adams PR (1976) Drug blockade of open end-plate channels. J Physiol (Lond) 260:531-552.

Akk G (2002) Contributions of the non- $\alpha$ subunit residues (loop D) to agonist binding and channel gating in the muscle nicotinic acetylcholine receptor. J Physiol (Lond) 544:695-705.

Akk G, Auerbach A (1999) Activation of muscle nicotinic acetylcholine receptor channels by nicotinic and muscarinic agonists. Br J Pharmacol 128:1467-1476.

Akk G, Steinbach JH (2000) Structural elements near the C-terminus are responsible for changes in nicotinic receptor gating kinetics following patch excision. J Physiol (Lond) 527:405-417.

Akk G, Steinbach JH (2003) Activation and block of mouse muscle-type nicotinic receptors by tetraethylammonium. J Physiol (Lond) 551:155-168.

Amin J, Weiss DS (1993) GABA $_{\mathrm{A}}$ receptor needs two homologous domains of the $\beta$-subunit for activation by GABA but not by pentobarbital. Nature 366:565-569.

Auerbach A, Akk G (1998) Desensitization of mouse nicotinic acetylcholine receptor channels. A two-gate mechanism. J Gen Physiol 112:181-197.

Auerbach A, Sigurdson W, Chen J, Akk G (1996) Voltage dependence of mouse acetylcholine receptor gating: different charge movements in di-, mono- and unliganded receptors. J Physiol (Lond) 494:155-170.

Brejc K, van Dijk WJ, Klaassen RV, Schuurmans M, van Der Oost J, Smit AB, Sixma TK (2001) Crystal structure of an ACh-binding protein reveals the ligand-binding domain of nicotinic receptors. Nature 411:269-276.

Chen J, Auerbach A (1998) A distinct contribution of the $\delta$ subunit to acetylcholine receptor channel activation revealed by mutations of the M2 segment. Biophys J 75:218-225.

Colquhoun D, Hawkes AG (1977) Relaxation and fluctuations of membrane currents that flow through drug-operated channels. Proc R Soc Lond B Biol Sci 199:231-262.

Colquhoun D, Sakmann B (1985) Fast events in single-channel currents activated by acetylcholine and its analogues at the frog muscle end-plate. J Physiol (Lond) 369:501-557.

Cooper JC, Gutbrod O, Witzemann V, Methfessel C (1996) Pharmacology of the nicotinic acetylcholine receptor from fetal rat muscle expressed in Xenopus oocytes. Eur J Pharmacol 309:287-298.

Dajas-Bailador FA, Heimala K, Wonnacott S (2003) The allosteric potentiation of nicotinic acetylcholine receptors by galantamine is transduced into cellular responses in neurons: $\mathrm{Ca}^{2+}$ signals and neurotransmitter release. Mol Pharmacol 64:1217-1226.

Grosman C, Salamone FN, Sine SM, Auerbach A (2000) The extracellular linker of muscle acetylcholine receptor channels is a gating control element. J Gen Physiol 116:327-340.

Hamill OP, Marty A, Neher E, Sakmann B, Sigworth FJ (1981) Improved patch-clamp techniques for high-resolution current recording from cells and cell-free membrane patches. Pflügers Arch 391:85-100.

Kawai H, Carlson BJ, Okita DK, Raftery MA (1999) Eserine and other tertiary amine interactions with Torpedo acetylcholine receptor postsynaptic membrane vesicles. Biochemistry 38:134-141.

Kopta C, Steinbach JH (1994) Comparison of mammalian adult and fetal nicotinic acetylcholine receptors stably expressed in fibroblasts. J Neurosci 14:3922-3933.

Maelicke A, Albuquerque EX (2000) Allosteric modulation of nicotinic acetylcholine receptors as a treatment strategy for Alzheimer's disease. Eur J Pharmacol 393:165-170.

Magleby KL, Stevens CF (1972) The effect of voltage on the time course of end-plate currents. J Physiol (Lond) 223:151-171.

Ogden DC, Colquhoun D (1985) Ion channel block by acetylcholine, carbachol and suberyldicholine at the frog neuromuscular junction. Proc R Soc Lond B Biol Sci 225:329-355.

Ohno K, Hutchinson DO, Milone M, Brengman JM, Bouzat C, Sine SM, Engel AG (1995) Congenital myasthenic syndrome caused by prolonged acetylcholine receptor channel openings due to a mutation in the M2 domain of the $\epsilon$ subunit. Proc Natl Acad Sci USA 92:758-762.

Okonjo KO, Kuhlmann J, Maelicke A (1991) A second pathway of activation of the Torpedo acetylcholine receptor channel. Eur J Biochem 200:671-677.

Pabreza LA, Dhawan S, Kellar KJ (1991) $\left[{ }^{3} \mathrm{H}\right]$ Cytisine binding to nicotinic cholinergic receptors in brain. Mol Pharmacol 39:9-12.

Pereira EF, Reinhardt-Maelicke S, Schrattenholz A, Maelicke A, Albuquerque 
EX (1993a) Identification and functional characterization of a new agonist site on nicotinic acetylcholine receptors of cultured hippocampal neurons. J Pharmacol Exp Ther 265:1474-1491.

Pereira EF, Alkondon M, Tano T, Castro NG, Froes-Ferrao MM, Rozental R, Aronstam RS, Schrattenholz A, Maelicke A, Albuquerque EX (1993b) A novel agonist binding site on nicotinic acetylcholine receptors. J Rec Res 13:413-436.

Pereira EF, Hilmas C, Santos MD, Alkondon M, Maelicke A, Albuquerque EX (2002) Unconventional ligands and modulators of nicotinic receptors. J Neurobiol 53:479-500.

Prince RJ, Pennington RA, Sine SM (2002) Mechanism of tacrine block at adult human muscle nicotinic acetylcholine receptors. J Gen Physiol 120:369-393.

Qin F, Auerbach A, Sachs F (1996) Estimating single-channel kinetic parameters from idealized patch-clamp data containing missed events. Biophys J 70:264-280.

Qin F, Auerbach A, Sachs F (1997) Maximum likelihood estimation of aggregated Markov processes. Proc R Soc Lond B Biol Sci 264:375-383.

Salamone FN, Zhou M, Auerbach A (1999) A re-examination of adult mouse nicotinic acetylcholine receptor channel activation kinetics. J Physiol (Lond) 516:315-330.

Samochocki M, Hoffle A, Fehrenbacher A, Jostock R, Ludwig J, Christner C, Radina M, Zerlin M, Ullmer C, Pereira EF, Lubbert H, Albuquerque EX, Maelicke A (2003) Galantamine is an allosterically potentiating ligand of neuronal nicotinic but not of muscarinic acetylcholine receptors. J Pharmacol Exp Ther 305:1024-1036.

Schrattenholz A, Godovac-Zimmermann J, Schafer HJ, Albuquerque EX, Maelicke A (1993) Photoaffinity labeling of Torpedo acetylcholine receptor by physostigmine. Eur J Biochem 216:671-677.

Schroder B, Reinhardt-Maelicke S, Schrattenholz A, McLane KE, Kretschmer
A, Conti-Tronconi BM, Maelicke A (1994) Monoclonal antibodies FK1 and WF6 define two neighboring ligand binding sites on Torpedo acetylcholine receptor $\alpha$-polypeptide. J Biol Chem 269:10407-10416.

Shaw KP, Aracava Y, Akaike A, Daly JW, Rickett DL, Albuquerque EX (1985) The reversible cholinesterase inhibitor physostigmine has channelblocking and agonist effects on the acetylcholine receptor-ion channel complex. Mol Pharmacol 28:527-538.

Sine S, Taylor P (1979) Functional consequences of agonist-mediated state transitions in the cholinergic receptor. Studies in cultured muscle cells. J Biol Chem 254:3315-3325.

Storch A, Schrattenholz A, Cooper JC, Ghani EMA, Gutbrod O, Weber KH, Reinhardt S, Lobron C, Hermsen B, Soskic V, Pereira EFR, Albuquerque EX, Methfessel C, Maelicke A (1995) Physostigmine, galanthamine and codeine act as noncompetitive nicotinic receptor agonists on clonal rat pheochromocytoma cells. Eur J Pharmacol 290:207-219.

Ueno S, Bracamontes J, Zorumski C, Weiss DS, Steinbach JH (1997) Bicuculline and gabazine are allosteric inhibitors of channel opening of the $\mathrm{GABA}_{\mathrm{A}}$ receptor. J Neurosci 17:625-634.

Wachtel RE (1993) Physostigmine block of ion channels activated by acetylcholine in BC3H1 cells. Mol Pharmacol 44:1051-1055.

Woodhull AM (1973) Ionic blockage of sodium channels in nerve. J Gen Physiol 61:687-708.

Zhou M, Engel AG, Auerbach A (1999) Serum choline activates mutant acetylcholine receptors that cause slow channel congenital myasthenic syndromes. Proc Natl Acad Sci USA 96:10466-10471.

Zwart R, van Kleef RG, Gotti C, Smulders CJ, Vijverberg HP (2000) Competitive potentiation of acetylcholine effects on neuronal nicotinic receptors by acetylcholinesterase-inhibiting drugs. J Neurochem 75: 2492-2500. 